\title{
Hibiscus cannabinus: efeitos nos parâmetros nutricionais e bioquímicos de ratos dislipidêmicos ${ }^{\#}$
}

Hibiscus cannabinus: effects on nutritional parameters and biochemical of rats dyslipidemic

Sandra Soares Melo* Danielli da Silva Chiarelli* Maria Luiza Laurentino*

\begin{abstract}
Resumo
A planta Hibiscus cannabinus ( $\mathrm{Hc}$ ) é utilizada na medicina popular para tratamentos inflamatórios. Poucas são as pesquisas que caracterizam o potencial anti-hiperlipidêmico desta planta, principalmente das flores. O objetivo do presente estudo foi avaliar o efeito do extrato seco das flores de Hc nos parâmetros nutricionais e bioquímicos de ratos dislipidêmicos. Foram utilizados 21 ratos machos e adultos, divididos em três grupos: Grupo C - dieta padrão; Grupo D - dieta hiperlipídica; Grupo DH - dieta hiperlipídica acrescida do extrato seco das flores de Hc. O estudo teve duração de sete semanas. Em duas semanas os animais dos Grupos D e DH receberam dieta hiperlipídica para indução da dislipidemia, posteriormente o Grupo DH recebeu tratamento com Hc (500mg/kg peso) por cinco semanas. O Grupo $\mathrm{C}$ recebeu dieta padrão (AIN-93M) durante o estudo. Os animais permaneceram em ambiente controlado, sendo coletado peso corporal, consumo alimentar, ingestão hídrica, excreção urinária e fecal. Ao final do estudo o sangue foi utilizado para determinações bioquímicas e o peso dos órgãos para comparação entre grupos. O Grupo $\mathrm{DH}$, na $7^{\underline{a}}$ semana de estudo, apresentou menor consumo alimentar comparado ao Grupo C e maior excreção fecal na $2^{\underline{a}}$ e 4 a semanas, em comparação aos Grupos C e D. As variáveis peso corporal, ingestão hídrica e excreção urinária não sofreram influência do extrato das flores de Hc. A dieta dislipidêmica elevou o peso do fígado nos Grupos $\mathrm{D}$ e $\mathrm{DH}$. O Hc não foi eficiente em manter os parâmetros de normalidade das variáveis estudadas, com exceção do consumo alimentar e excreção fecal.
\end{abstract}

Palavras-chave: Dislipidemias. Hibiscus. Plantas Medicinais.

\begin{abstract}
The plant Hibiscus cannabinus ( $\mathrm{Hc}$ ) is used in folk medicine for inflammatory treatments. There are few studies that characterize the anti-hyperlipidemic potential of this plant, mainly flowers. The aim of this study was to evaluate the effect of dry extract of Hc flowers in nutritional and biochemical parameters of dyslipidemic mice. 21 male rats and adults were divided into three groups: Group C - standard diet; Group D - fat diet; DH Group - plus fat diet dry extract of Hc flowers. The study lasted seven weeks. In two weeks the animals in Groups D and DH received high fat diet for induction of dyslipidemia, then the $\mathrm{DH}$ group received treatment with $\mathrm{Hc}$ (500mg / kg weight) for five weeks. Group C received standard diet (AIN-93M) during the study. The animals were kept in a controlled environment, being collected body weight, food intake, water intake, urinary and fecal excretion. At the end of the study the blood was used for biochemical determinations and weight of organs for comparison between groups. The DH Group, the 7 th week of the study, showed lower food consumption compared to Group C and increased fecal excretion in the 2nd and 4th weeks, compared to Groups C and D. The variables body weight, water intake and urinary excretion were not influenced the Hc extract of flowers. The dyslipidemic diet increased liver weight in Groups D and DH. The Hc was not effective in maintaining the normal parameters of the variables studied, with the exception of food and fecal excretion consumption.
\end{abstract}

Keywords: Dyslipidemias. Hibiscus. Medicinal Plants.

DOI: 10.15343/0104-7809.201640011120

"Esta pesquisa foi financiada pela Empresa de Pesquisa Agropecuária e Extensão Rural de Santa Catarina em Itajaí (EPAGRI), Itajaí, SC, Brasil.

* Universidade do Vale do Itajaí - UNIVALI, Itajaí, SC - BRASIL. E-mail: ssmelo@gmail.com

As autoras declaram não haver conflitos de interesse. 


\section{INTRODUÇÃO}

A dislipidemia é um fator de risco altamente preditivo para aterosclerose, doenças da artéria coronária e doenças vasculares cerebrais, sendo caracterizada pela elevação das concentrações séricas de colesterol total, triglicérideos e densidade (LDL-colesterol) e lipoproteina de muito baixa densidade (VLDL-colesterol) e diminuição da lipoproteína de alta densidade (HDL-colesterol) ${ }^{1}$.

O controle da dislipidemia pode ser atingido por meio de cuidados dietéticos associados a mudanças no estilo de vida, sendo em alguns casos também necessário o tratamento farmacológico. No entanto, a alimentação é reconhecida como a intervenção mais importante na redução de risco e tratamento da dislipidemia ${ }^{2}$.

Produtos derivados de plantas são importantes recursos terapêuticos no tratamento de muitas doenças. Dados da Organização Mundial de Saúde mostram que $70-80 \%$ da população mundial faz uso terapêutico de extratos de plantas medicinais ${ }^{3}$.

O Hibiscus sp., um gênero importante da Família Malvaceae, tem mais de 220 espécies distribuídas em regiões tropicais e subtropicais ${ }^{4}$. Estas plantas têm sido utilizadas na forma de chás na medicina popular, com fins profiláticos e terapêuticos. São atribuídas atividades antifúngica; hipocolesterolêmica; diurética; laxante ${ }^{5}$; antibacteriana, anti-hipertensiva 6,7. Dentre essas espécies, o Hibiscus cannabinus L., conhecido popularmente como cânhamobrasileiro ou Kenaf, tem sua origem na África tropical, porém seu cultivo se estendeu ao Continente Asiático, Europeu, Americano, incluindo o Brasil ${ }^{5,6,7}$.

O Hibiscus cannabinus era tradicionalmente prescrito na medicina popular da África e Índia por conter vários componentes ativos como taninos, saponinas, polifenóis, alcaloides, óleos essenciais e esteroides. Durante séculos, esta planta foi usada como antídoto para envenenamento por produtos químicos (ácidos, álcalis, pesticidas) e cogumelos venenosos; para tratar contusões, doenças biliares, febre e puerpério $^{8}$.

$\mathrm{O}$ óleo da semente de Hibiscus

cannabinus isolado e encapsulado, além do extrato da semente demonstrou efeito antihipercolesterolêmico comparável com droga hipocolesterolêmica comercial ${ }^{6}$. O extrato da casca era aplicado no tratamento de diarreia e inflamações na garganta. $O$ uso tópico das sementes era indicado para tratar dores e contusões ${ }^{9}$. Estudos com a fração do óleo essencial desta planta mostrou atividade fitotóxica e fungitóxica ${ }^{10}$; o extrato aquoso das folhas demonstrou potencial antioxidativo e hepatoprotetor frente ao tetracloreto de carbono e ao paracetamol em ratos ${ }^{8,9}$. Além disso, o extrato etanólico a $80 \%$ das folhas mostrou atividade imunomoduladora significativa em macrófagos ${ }^{9}$. O extrato hidroalcoólico a $50 \%$ das folhas exibiu forte atividade anti-hiperlipidêmica dose dependente, e $400 \mathrm{mg} / \mathrm{Kg}$ mostrou redução significativa das concentrações séricas de triglicérides, colesterol total, LDL-c, VLDL-c e substâncias reativas ao ácido tiobarbitúrico. Em adição, o extrato preveniu a esteatose hepática em ratos dislipidêmicos ${ }^{11}$.

As flores do Hibiscus cannabinus são fontes de antocianinas, além de outros compostos bioativos $^{12}$, entretanto poucos estudos in vivo têm sido conduzidos com esta parte da planta.

Diante do exposto, o presente estudo teve como objetivo avaliar o efeito do extrato bruto das flores de Hibiscus cannabinus nos parâmetros nutricionais e bioquímicos de ratos recebendo dieta hiperlipídica.

\section{METODOLOGIA}

O projeto foi desenvolvido no Laboratório de Nutrição Experimental do Curso de Nutrição da Universidade do Vale do Itajaí - UNIVALI, aprovado pela Comissão de Ética sob nº do protocolo CEUA 07/14 desta instituição. Os procedimentos adotados para a utilização de ratos com fins científicos foram realizados segundo a Lei no 11.794 de 2008.

\section{Animais}

Foram estudados 21 ratos machos, adultos, da linhagem Wistar (Rattus norvegicus), variação albinus, com 90 dias de vida, pesando em média 173,62g com desvio padrão de 8,90g, provenientes do Biotério Central da UNIVALI. 
Os animais foram divididos em blocos ao acaso em três grupos: Grupo Controle (C) dieta padrão; Grupo induzido à dislipidemia (D) - dieta hiperlipídica; Grupo induzido à dislipidemia e tratado com Hibiscus cannabinus (DH) - dieta hiperlipídica acrescida de extrato seco das flores de Hibiscus cannabinus.

\section{Dietas}

A planta Hibiscus cannabinus foi cultivada e fornecida pela Empresa de Pesquisa Agropecuária e Extensão Rural de Santa Catarina (EPAGRI). As flores utilizadas foram secas em estufa de circulação com ar forçado, trituradas na forma de pó e posteriormente acrescidas na dieta na quantidade de 500mg/ $\mathrm{kg}$ do peso do rato.

A dieta padrão oferecida ao Grupo Controle foi preparada de acordo com a recomendação do American Institute of Nutrition 1993 ${ }^{13}$, para a manutenção de ratos adultos (AIN-93M).

O ensaio biológico foi dividido em duas fases: indução da dislipidemia e tratamento. Para a indução da dislipidemia utilizou-se 14 ratos. Estes receberam dieta hiperlipídica e água ad libitum por sete semanas. A dieta hiperlipídica foi preparada com banha suína na quantidade de $10 \%$, colesterol sintético $\left(\right.$ Roche $\left.^{\mathrm{R}}\right)$ em $1 \%$ e ácido cólico $\left(\right.$ Roche $\left.^{R}\right)$ em $0,1 \%$, adicionados à dieta AIN-93 $\mathrm{M}^{13}$. Após a indução os animais do Grupo DH receberam adição da espécie alvo por cinco semanas de estudos.

\section{Dlineamento experimental}

Os animais foram mantidos em período de adaptação ao ambiente, por cinco dias, antes do início do experimento, permitindo acesso livre à alimentação (dieta comercial peletizada) e água.

Neste experimento os ratos foram induzidos à dislipidemia por duas semanas e tratados por cinco semanas. Durante o experimento os animais foram mantidos em gaiolas metabólicas de aço inoxidável em sala fechada, com temperatura controlada $\left(22 \pm 2^{\circ} \mathrm{C}\right)$, com fotoperíodo de 12 horas.

No decorrer das sete semanas de estudo foram avaliados os parâmetros nutricionais de peso corporal, consumo alimentar, ingestão hídrica, volume urinário e excreção fecal.

No $48^{\circ}$ dia de experimento os animais, em jejum de oito a doze horas, foram anestesiados com Cloridrato de Cetamina $75 \mathrm{mg} / \mathrm{kg}$; Cloridrato de Xilazina $10 \mathrm{mg} / \mathrm{kg}$ e Acepromazina $5 \mathrm{mg} / \mathrm{kg}$ de peso corporal ${ }^{14}$. Após a eutanásia o sangue foi coletado por punção cardíaca do ventrículo direito, centrifugado a 3000 rotações por minuto a temperatura ambiente, por quinze minutos para a obtenção do soro. Foram determinadas as concentrações de colesterol total, lipoproteína de alta densidade (HDLcolesterol), triglicerídeos, glicose, aspartato aminotransferase, alanina aminotransferase, fosfatase alcalina e creatinina, utilizando kit comercial de acordo com o protocolo do fabricante usando um analisador Cobas Mira Plus, Roche ${ }^{\mathrm{R}}$.

Após a eutanásia foram extraídos os seguintes órgãos: fígado, rim, pâncreas, baço e coração para comparações de peso entre os grupos experimentais. Os órgãos foram coletados, lavados em solução salina gelada, colocados sob papel filtro e imediatamente pesados em balança de precisão para comparação entre grupos experimentais.

\section{Análise Estatística}

Os resultados foram apresentados em médias e desvios padrão e submetidos à Análise de Variância (ANOVA), bicaudal, com o pósteste de Tukey-Kramer para a comparação de médias entre os grupos. Foram consideradas significativas as diferenças com $p<0,05$. A análise estatística foi realizada com auxílio do programa Graph Pad Instat, versão 3,0.

\section{RESULTADOS}

A Tabela 1 evidencia os dados de consumo alimentar dos animais experimentais ao longo das sete semanas de estudo. Observou-se diferença significativa na sétima semana, sendo que o Grupo DH mostrou menor consumo alimentar em comparação ao Grupo C. Na quarta e quinta semanas os Grupos D e DH, tenderam a apresentar menor consumo alimentar quando comparados ao Grupo C.

A Tabela 2 apresenta a ingestão hídrica dos animais no período do experimento. Não se identificou diferenças estatísticas entre os grupos.

A excreção urinária dos animais durante o
13

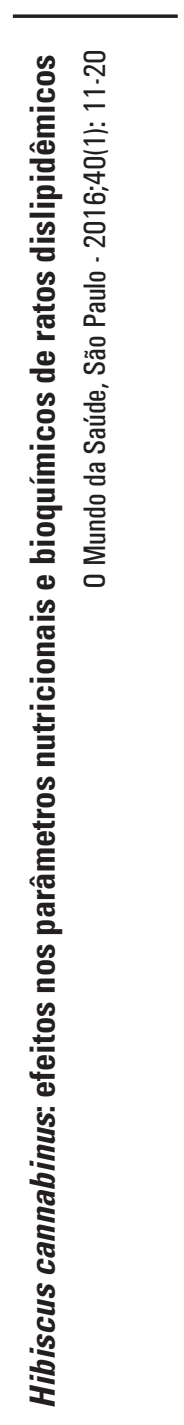


experimento pode ser visualizada na Tabela 3. Constatou-se diferença significativa na sexta semana, sendo que o Grupo D apresentou menor média quando comparado com o Grupo C.

A Tabela 4 apresenta a excreção fecal dos animais no decorrer do estudo. Na segunda semana o Grupo DH exibiu maior valor em comparação ao Grupo C. Na quarta semana o Grupo DH mostrou maior valor de excreção fecal em relação ao Grupo D.

A Tabela 5 indica o peso dos órgãos dos animais ao final do experimento. Observouse diferença significativa para os Grupos $\mathrm{DH}$ e $\mathrm{D}$, com maiores médias de peso do fígado, em comparação ao Grupo C.

A Tabela 6 expõe os resultados dos exames laboratoriais dos animais estudados. Observou-se diferenças significativas entre os grupos para as concentrações séricas colesterol, triglicerídeos, fosfatase alcalina (FAL), aspartato aminotransferase (AST), alanina aminotransferase (ALT) e creatinina.

Quanto às concentrações séricas de colesterol, ALT e creatinina os Grupos D e DH diferiram estatisticamente do Grupo C, com maiores médias. Em relação aos valores de triglicerídeos os Grupos D e DH apresentaram menores médias em comparação ao Grupo C. O Grupo DH apresentou maior média em relação aos Grupos $\mathrm{C}$ e $\mathrm{D}$, quanto às concentrações séricas de FAL e para as concentrações séricas de AST somente o Grupo DH diferiu do Grupo C.

A Figura 1 demonstra o ganho de peso dos diferentes animais experimentais ao final do estudo. Os grupos não diferenciaram estatisticamente entre si.

Tabela 1 - Médias e desvios padrão do consumo alimentar (g/dia) dos diferentes grupos experimentais durante o estudo. Laboratório de Nutrição Experimental, UNIVALI, Itajaí/SC, maio/junho de 2014.

\begin{tabular}{ccccc}
\hline Semanas & $\mathbf{C}$ & $\mathbf{D}$ & $\mathbf{D H}$ & Valor de $\mathbf{p}$ \\
\hline $1^{\underline{a}}$ & $22,59(2,11)$ & $23,59(1,52)$ & $23,13(2,00)$ & 0,6233 \\
$2^{\underline{a}}$ & $23,96(1,27)$ & $23,23(2,13)$ & $21,94(3,23)$ & 0,2883 \\
$3^{\underline{a}}$ & $25,08(1,15)$ & $23,48(1,09)$ & $23,60(3,09)$ & 0,2773 \\
$4^{\underline{a}}$ & $26,48(2,39)$ & $23,61(1,80)$ & $23,68(2,71)$ & 0,0535 \\
$5^{\underline{a}}$ & $26,09(2,11)$ & $23,63(2,08)$ & $24,75(1,01)$ & 0,0627 \\
$6^{\underline{a}}$ & $24,97(1,63)$ & $24,67(1,67)$ & $23,46(1,80)$ & 0,2408 \\
$7^{\underline{a}}$ & $25,68(0,95)^{\mathrm{a}}$ & $23,01(2,42)^{\mathrm{ab}}$ & $22,83(2,43)^{\mathrm{b}}$ & $\mathbf{0 , 0 3 1 3}$ \\
\hline
\end{tabular}

Legenda: Grupo C: Controle; Grupo D: Dislipidemia; Grupo DH: Dislipidemia tratado com Hibiscus cannabinus.

Análise estatística: letras diferentes representam diferenças estatisticamente significativas, entre grupos com $\mathrm{p}<0,05$.

Tabela 2 - Médias e desvios padrão do consumo hídrico $(\mathrm{mL} / \mathrm{dia})$ de diferentes grupos experimentais no decorrer das sete semanas de estudo. Laboratório de Nutrição Experimental, UNIVALI, Itajaí/SC, maio/junho de 2014.

\begin{tabular}{ccccc}
\hline Semanas & C & D & DH & Valor de $\mathbf{p}$ \\
\hline $1^{\underline{a}}$ & $33,57(16,81)$ & $33,07(17,64)$ & $27,04(13,68)$ & 0,7053 \\
$2^{\underline{a}}$ & $33,71(15,75)$ & $23,57(14,04)$ & $21,07(9,57)$ & 0,2070 \\
$3^{\underline{a}}$ & $26,36(9,15)$ & $25,05(9,41)$ & $27,13(10,99)$ & 0,9241 \\
$4^{\underline{a}}$ & $30,83(10,95)$ & $30,71(9,64)$ & $32,94(9,42)$ & 0,8962 \\
$5^{\underline{a}}$ & $31,95(10,70)$ & $28,60(8,09)$ & $29,22(7,01)$ & 0,7518 \\
$6^{\underline{a}}$ & $33,78(7,21)$ & $25,40(8,32)$ & $28,89(6,97)$ & 0,1405 \\
$7^{\underline{a}}$ & $30,11(16,90)$ & $21,64(11,26)$ & $28,11(12,10)$ & 0,4932 \\
\hline
\end{tabular}

Legenda: Grupo C: Controle; Grupo D: Dislipidemia; Grupo DH: Dislipidemia tratado com Hibiscus cannabinus. 
Tabela 3 - Médias e desvios padrão da excreção urinária $(\mathrm{mL} / \mathrm{dia})$ dos diferentes grupos experimentais ao longo do estudo. Laboratório de Nutrição Experimental, UNIVALI, Itajaí/SC, maio/junho de 2014.

\begin{tabular}{ccccc}
\hline Semanas & $\mathbf{C}$ & $\mathbf{D}$ & $\mathbf{D H}$ & Valor de $\mathbf{p}$ \\
\hline $1^{\mathrm{a}}$ & $34,29(32,08)$ & $15,86(10,09)$ & $17,71(10,82)$ & 0,2051 \\
$2^{\text {a }}$ & $31,57(25,26)$ & $24,14(19,39)$ & $15,57(11,89)$ & 0,3343 \\
$3^{\text {a }}$ & $22,29(20,84)$ & $11,29(6,16)$ & $11,14(5,87)$ & 0,2120 \\
$4^{\text {a }}$ & $12,86(7,47)$ & $11,43(14,06)$ & $15,14(9,26)$ & 0,8068 \\
$5^{\text {a }}$ & $16,43(7,50)$ & $12,00(7,14)$ & $14,86(9,26)$ & 0,5873 \\
$6^{\underline{a}}$ & $22,14(10,51) \mathrm{a}$ & $9,14(3,44) \mathrm{b}$ & $13,00(8,17) \mathrm{ab}$ & $\mathbf{0 , 0 1 9 3}$ \\
$7^{\mathrm{a}}$ & $20,00(16,77)$ & $7,71(3,59)$ & $14,71(8,36)$ & 0,1408 \\
\hline
\end{tabular}

Legenda: Grupo C: Controle; Grupo D: Dislipidemia; Grupo DH: Dislipidemia tratado com Hibiscus cannabinus.

Anбlise estathstica: letras diferentes representam diferenças estatisticamente significativas, entre grupos com $p<0,05$.

Tabela 4 - Médias e desvios padrão da excreção fecal (g/dia) dos diferentes grupos experimentais no decorrer do estudo. Laboratório de Nutrição Experimental, UNIVALI, Itajaí/SC, maio/junho de 2014.

\begin{tabular}{ccccc}
\hline Semanas & $\mathbf{C}$ & $\mathbf{D}$ & $\mathbf{D H}$ & Valor de $\mathbf{p}$ \\
\hline $1^{\underline{\underline{a}}}$ & $1,65(0,73)$ & $1,56(0,71)$ & $1,68(0,92)$ & 0,9542 \\
$2^{\underline{a}}$ & $1,46(0,33) \mathrm{a}$ & $1,83(0,39) \mathrm{ab}$ & $2,35(0,71) \mathrm{b}$ & 0,0133 \\
$3^{\underline{a}}$ & $1,45(0,49)$ & $1,62(0,48)$ & $1,60(0,58)$ & 0,7984 \\
$4^{\underline{a}}$ & $1,56(0,41) \mathrm{ab}$ & $1,53(0,32) \mathrm{a}$ & $2,04(0,45) \mathrm{b}$ & 0,0464 \\
$5^{\underline{a}}$ & $1,57(0,27)$ & $1,59(0,53)$ & $1,60(0,34)$ & 0,9904 \\
$6^{\underline{a}}$ & $1,70(0,45)$ & $1,60(0,34)$ & $1,94(0,41)$ & 0,3096 \\
$7^{\underline{a}}$ & $1,50(0,28)$ & $1,66(0,23)$ & $1,63(0,31)$ & 0,5148 \\
\hline
\end{tabular}

Legenda: Grupo C: Controle; Grupo D: Dislipidemia; Grupo DH: Dislipidemia tratado com Hibiscus cannabinus.

Análise estatística: letras diferentes representam diferenças estatisticamente significativas, entre grupos com $\mathrm{p}<0,05$.

Tabela 5 - Médias e desvios padrão do peso dos órgãos dos animais experimentais no final do estudo. Laboratório de Nutrição Experimental, UNIVALI, Itajaí/SC, maio/junho de 2014.

\begin{tabular}{ccccc}
\hline Órgãos & $\mathbf{C}$ & $\mathbf{D}$ & $\mathbf{D H}$ & Valor de p \\
\hline Baço & $0,95(0,18)$ & $1,30(0,26)$ & $1,30(0,45)$ & 0,0885 \\
Coração & $0,99(0,06)$ & $1,04(0,11)$ & $0,92(0,10)$ & 0,0804 \\
Fígado & $12,66(1,76) \mathrm{a}$ & $24,25(2,60) \mathrm{b}$ & $22,55(3,21) \mathrm{b}$ & $\mathbf{0 , 0 0 0 1}$ \\
Pâncreas & $0,61(0,11)$ & $0,58(0,10)$ & $0,71(0,28)$ & 0,3680 \\
Rim & $1,24(0,24)$ & $1,24(0,11)$ & $1,25(0,22)$ & 0,9962 \\
\hline
\end{tabular}

Legenda: Grupo C: Controle; Grupo D: Dislipidemia; Grupo DH: Dislipidemia tratado com Hibiscus cannabinus.

Análise estatística: letras diferentes representam diferenças estatisticamente significativas, entre grupos com $\mathrm{p}<0,05$. 
Tabela 6 - Médias e desvios padrão dos exames bioquímicos dos diferentes grupos experimentais ao final do estudo. Laboratório de Nutrição Experimental, UNIVALI, Itajaí/SC, maio/junho de 2014.

\begin{tabular}{lcccc}
\hline \multicolumn{1}{c}{ Exames } & C & D & DH & Valor de p \\
\hline Glicose $(\mathrm{mg} / \mathrm{dL})$ & $413,43(122,48)$ & $359,57(115,79)$ & $307,86(74,68)$ & 0,2069 \\
Triglicerídeos $(\mathrm{mg} / \mathrm{dL})$ & $194,86(87,24) \mathrm{a}$ & $60,43(20,24) \mathrm{b}$ & $47,71(8,16) \mathrm{b}$ & 0,0001 \\
Colesterol (mg/dL) & $55,86(12,77) \mathrm{a}$ & $129,43(13,97) \mathrm{b}$ & $136,57(10,34) \mathrm{b}$ & 0,0001 \\
HDL-c $(\mathrm{mg} / \mathrm{dL})$ & $18,86(8,97)$ & $15,00(4,04)$ & $17,29(3,99)$ & 0,5092 \\
FAL $(\mathrm{mg} / \mathrm{dL})$ & $54,43(23,13) \mathrm{a}$ & $109,29(8,16) \mathrm{b}$ & $158,86(29,56) \mathrm{c}$ & 0,0001 \\
AST $(\mathrm{U} / \mathrm{L})$ & $132,06(30,82) \mathrm{a}$ & $165,00(24,11) \mathrm{ab}$ & $185,37(32,63) \mathrm{b}$ & 0,0110 \\
ALT $(\mathrm{U} / \mathrm{L})$ & $35,43(4,44) \mathrm{a}$ & $63,34(24,93) \mathrm{b}$ & $58,51(10,09) \mathrm{b}$ & 0,0085 \\
Creatinina $(\mathrm{mg} / \mathrm{dL})$ & $0,47(0,14) \mathrm{a}$ & $0,72(0,69) \mathrm{b}$ & $0,62(0,08) \mathrm{b}$ & 0,0008 \\
\hline
\end{tabular}

Legenda: Grupo C: Controle; Grupo D: Dislipidemia; Grupo DH: Dislipidemia tratado com Hibiscus cannabinus

Análise estatística: letras diferentes representam diferenças estatisticamente significativas, entre grupos com $\mathrm{p}<0,05$.

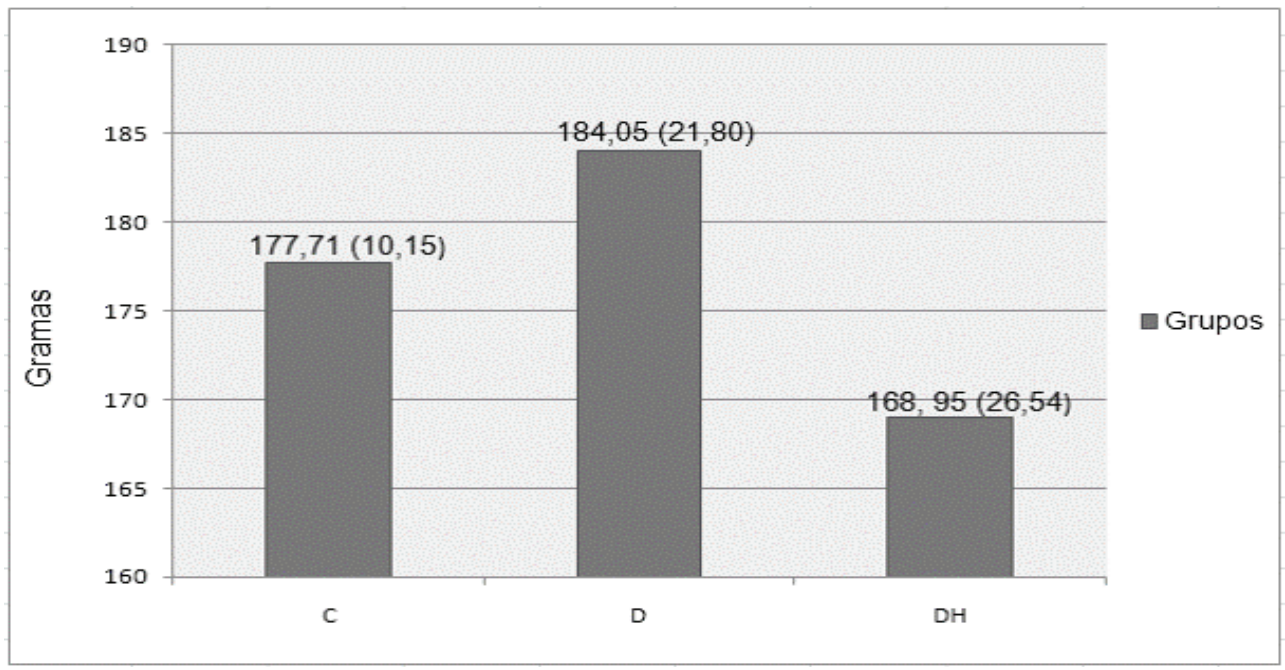

Legenda: Grupo C: Controle; Grupo D: Dislipidemia; Grupo DH: Dislipidemia tratado com Hibiscus cannabinus.

Figura 1 - Médias e desvios padrão do ganho de peso (g) dos diferentes grupos experimentais ao final das sete semanas de experimento. Laboratório de Nutrição Experimental, UNIVALI, Itajaí/SC, maio/ junho de 2014.

\section{DISCUSSÃO}

O presente trabalho avaliou o efeito do extrato seco das flores de Hibiscus cannabinus na dislipidemia em ratos Wistar adultos. Foram analisados os parâmetros nutricionais como consumo alimentar, peso corporal, ingestão hídrica, excreção urinaria e fecal, peso dos órgãos e parâmetros bioquímicos.

Em relação ao consumo alimentar observouse que o extrato seco das flores de Hibiscus cannabinus quando adicionado à dieta 
dislipidêmica reduziu significativamente a média desta variável no Grupo $\mathrm{DH}$, na $7^{\text {a }}$ semana de estudo, em comparação ao Grupo C. Na $4^{a}$ e $5^{\text {a }}$ semanas os animais que receberam dieta com maior aporte de gordura (Grupos D e DH) tenderam a consumir menor quantidade de dieta em comparação ao Grupo C.

O Hibiscus cannabinus têm sido usado na medicina popular por conter vários componentes ativos como taninos, saponinas, polifenóis, alcaloides, lignanas, óleos essenciais e esteroides ${ }^{8}$. As flores do Hibiscus cannabinus contêm glicosídeos cannabiscitrina, cannabiscetina, cannabinidina e antocianinas ${ }^{12}$. Lignanas foram isoladas a partir do extrato de acetona do cálice e a partir do extrato de acetona da casca $^{8}$. Entretanto, na literatura poucos artigos científicos foram encontrados sobre a composição nutricional do Hibiscus cannabinus, incluindo os valores das fibras nas suas flores.

Os cálices de outra espécie do mesmo gênero, o Hibiscus sabdariffa, mostrou elevado teor de fibra dietética $(33,9 \%)$, um dos principais componentes desta parte da planta ${ }^{15}$. A ingestão de fibras e a capacidade antioxidante são consideradas como alguns dos indicadores de uma dieta saudável ${ }^{16}$.

No presente estudo sugere-se que a inclusão de extrato seco das flores de Hibiscus cannabinus na dieta, particularmente a fibra presente nesta planta, pode ter exercido efeito na redução do consumo alimentar por oferecer saciedade, além do efeito sacietogênico da dieta dislipidêmica.

Em adição, a tendência a menor ingestão de alimentos pelos Grupos D e DH pode ser decorrente da maior quantidade de calorias contidas na dieta dislipidêmica $(4140,9$ kcal/ $\mathrm{kg}$ de dieta dislipidêmica x $3601 \mathrm{kcal} / \mathrm{kg}$ dieta controle) ${ }^{13}$. As dietas foram oferecidas "ad libitum", e observou-se tendência de menor ingestão ( $4^{\underline{a}}$ e $5^{\underline{a}}$ semanas) nos Grupos dislipidêmicos (Grupo D) por ser uma dieta hipercalórica, confirmando a hipótese segundo a qual os animais controlam sua ingestão em função das necessidades energéticas ${ }^{17}$.

Quanto aos dados de peso corporal não se observou efeito significativo do extrato seco das flores de Hibiscus cannabinus adicionado à dieta dislipidêmica.
Alarcon et al. ${ }^{18}$ realizaram estudos com camundongos para avaliar o efeito do extrato aquoso do cálice de Hibiscus sabdariffa em relação ao peso corporal de animais obesos. $\mathrm{O}$ extrato de Hibiscus sabdariffa, contendo 33,64 $\mathrm{mg}$ de antocianinas totais para cada $120 \mathrm{mg}$ de extrato, foi administrado por via oral (120mg/ $\mathrm{kg} / \mathrm{dia}$ ), durante 60 dias para os camundongos saudáveis e obesos. O Hibiscus sabdariffa apresentou componentes ativos como as antocianinas, reduziu o ganho de peso dos animais obesos e aumentou a ingestão hídrica em camundongos saudáveis e obesos.

Desta forma sugere-se que o extrato bruto das flores de Hibiscus cannabinus, mesmo reduzindo significativamente $\mathrm{O}$ consumo alimentar dos animais na $7^{\underline{a}}$ semana do estudo, não alterou o peso corporal. Entretanto, o Grupo DH exibiu menor valor médio de peso corporal (-4,93\%) em relação ao Grupo C, enquanto que o Grupo D mostrou aumento do valor médio de ganho de peso de 3,57\% comparado ao Grupo C.

Não houve diferença significativa na ingestão hídrica entre os grupos. Entretanto, para os valores de excreção urinária o Grupo que recebeu dieta dislipidêmica (Grupo D) apresentou menor média na $6^{\mathrm{a}}$ semana de estudo, em relação ao Grupo C. Conclui-se, que o Hibiscus cannabinus não exerceu influência significativa nas variáveis ingestão hídrica e excreção urinária.

Em relação à excreção fecal observou-se que o Grupo DH, que recebeu dieta adicionada de extrato seco das flores de Hibiscus cannabinus apresentou maiores médias em comparação ao Grupo C e Grupo D, na $2^{\underline{a}}$ e $4^{\underline{a}}$ semanas, respectivamente.

Estudos clínicos e epidemiológicos indicam a contribuição de fibra dietética encontrada no cálice do Hibiscus sabdariffa na manutenção da saúde gastrointestinal, na diminuição do risco de doenças cardiovasculares e de vários tipos de câncer. Alguns dos efeitos das fibras alimentares são atribuídos a sua capacidade de ser solubilizada em água, aumentando o trânsito intestinal, por reterem vários componentes alimentares e por serem degradadas pelas bactérias intestinais por fermentação colônica ${ }^{19}$.

Deste modo, sugere-se que a maior excreção fecal observada no Grupo $\mathrm{DH}$ pode
17 
ser atribuída a presença de fibras nas flores de Hibiscus cannabinus.

Conforme os resultados apresentados os Grupos D e DH apresentaram maior média de peso do fígado comparados ao Grupo C, podendo indicar, possivelmente, acúmulo de gordura hepática. O Grupo D elevou o peso médio do fígado em 91,54\% e o Grupo DH em $78,12 \%$, quando comparados ao Grupo C.

O fígado é um órgão central nos processos metabólicos e exerce múltiplas e importantes funções, centralizando a maior parte do processo homeostásico do organismo. Participa dos processos de digestão e de absorção intestinal por meio da síntese dos ácidos biliares e também possui relevante papel no metabolismo dos carboidratos, das proteínas e dos nucleotídeos, além de funções fundamentais na detoxificação de metabólitos ${ }^{20}$. Além disso, o fígado é o único órgão responsável pela síntese de gorduras e de reserva provenientes do excesso de carboidratos da dieta. Dietas ricas em gordura favorecem a formação de cálculos biliares e esteatose hepática ${ }^{21,22}$.

O extrato seco das flores de Hibiscus cannabinus associado à dieta dislipidêmica elevou as concentrações séricas de FAL dos animais do Grupo DH em comparação aos Grupos C e D. Além disto, o Grupo D apresentou maiores médias de FAL em comparação ao Grupo C. Sugere-se que o Hibiscus cannabinus adicionado à dieta dislipidêmica apresentou maior efeito que a dieta rica em gordura (Grupo D) em elevar as concentrações séricas de FAL, um marcador de toxicidade hepática ${ }^{23,24}$. A adição de gordura na dieta dos animais elevou as concentrações séricas de colesterol, ALT e creatinina no Grupo D em comparação ao Grupo C.

Alterações na atividade das enzimas alanina aminotransferase (ALT) e aspartato aminotransferase (AST) são importantes marcadores de doenças ou lesão tecidual, especificamente no fígado ${ }^{25}$. Porém, estas enzimas possuem ampla distribuição em tecidos como cérebro, coração e rim. Dietas ricas em colesterol promovem aumento no estresse oxidativo no fígado ${ }^{26}$, resultando em aumento na atividade destas enzimas.

Alanina aminotransferase (ALT)

encontrada principalmente no citoplasma do hepatócito, enquanto $80 \%$ da aspartato aminotransferase (AST) estão presentes na mitocôndria. Essa diferença tem auxiliado no diagnóstico e prognóstico de doenças hepáticas. Em dano hepatocelular leve a forma predominante no soro é a citoplasmática enquanto em lesões graves há liberação da enzima mitocondrial, elevando a relação AST/ ALT27. Analisando a relação de AST/ ALT, o Grupo C apresentou 3,72; o Grupo D 2,60 e o Grupo DH 3,17. Ressalta-se que o Grupo DH apresentou relação AST/ALT mais próxima do Grupo C, sugerindo menor dano hepático nos animais que receberam dieta hiperlipídica acrescida de extrato seco das flores de Hibiscus cannabinus em comparação aos ratos que receberam somente dieta rica em gordura (Grupo D).

Concentrações séricas de colesterol total e creatinina mais elevadas nos Grupos D e DH foram identificadas, em relação ao Grupo C. Dietas ricas em gordura, principalmente gordura saturada e colesterol, são responsáveis pelo aumento das doenças como obesidade, diabetes, problemas cardiovasculares, hipertensão e câncer. As concentrações de colesterol total e da fração LDL-colesterol podem ser elevadas no sangue pelo consumo de calorias em excesso, gorduras saturadas, colesterol e possivelmente, proteína animal. As taxas séricas podem ser reduzidas por diminuição do peso corporal, substituição de alimentos ricos em ácidos graxos saturados por ácidos graxos poliinsaturados e aumento do consumo de fibra alimentar, especialmente a fração solúvel, que apresenta importante efeito hipocolesterolemiante podendo reduzir assim, o risco de doenças coronarianas ${ }^{28}$.

A creatinina é produzida como resultado da desidratação não-enzimática da creatina muscular. A creatinina encontra-se no sangue e na urina, por sua vez, é sintetizada no fígado, rim e pâncreas e transportada para as células musculares e cérebro, onde é fosforilada à creatina-fosfato (substância que atua como reservatório de energia). Tanto a creatina-fosfato como a creatina, em condições fisiológicas, espontaneamente perdem o ácido fosfórico ou água, respectivamente, para formar seu anidrido, a creatinina. A creatinina livre não 
é reutilizada no metabolismo corporal e assim funciona somente como um produto dos resíduos de creatina.

A creatinina difunde do músculo para o plasma onde é removida quase inteiramente e em velocidade relativamente constante por filtração glomerular. Em presença de teores marcadamente elevados de creatinina no plasma, parte da mesma é também excretada pelos túbulos renais. Concentrações de creatinina são afetadas pela dieta dislipidêmica, indicando possível comprometimento da função do fígado ${ }^{29}$.

\section{CONSIDERAÇÕES FINAIS}

Conclui-se que o extrato seco das flores de Hibiscus cannabinus acrescido na dieta dislipidêmica proporcionou menor consumo alimentar e maior excreção fecal aos animais, entretanto, sem alterar significativamente os parâmetros bioquímicos.

Esse trabalho foi pioneiro em avaliar o efeito
Desta forma, sugere-se que o extrato seco das flores de Hibiscus cannabinus não exerceu efeito positivo nos exames laboratoriais frente à dislipidemia induzida por acréscimo de gordura na dieta, colesterol e ácido cólico.

Como limitação do presente estudo ressalta-se que o rato não é o melhor modelo para se trabalhar com dislipidemia, por este controlar sua ingestão em função das necessidades energéticas ${ }^{17}$. Porém, o metabolismo do rato é próximo ao ser humano em todos os demais aspectos, além de ser um modelo biológico de fácil reprodução e manejo.

do extrato seco das flores de Hibiscus cannabinus na dislipidemia induzida em animais.

Sugere-se a realização de estudos adicionais que possam avaliar a composição nutricional do Hibiscus cannabinus, incluindo a quantidade e tipo de fibras presentes nas flores desta espécie. Em adição, sugere-se a reprodução deste tipo de estudo experimental com maiores quantidades de extrato seco das flores de Hibiscus cannabinus por peso do animal.

\section{REFERÊNCIAS}

\footnotetext{
1 Tilak KS, Veeraiah K, Koteswara Rao DK. Restoration on tissue antioxidants by fenugreek seeds (Trigonella foenum Graecum) in alloxan-diabetic rats. Indian J Physiol Pharmacol. 2001; 45: 408- 420

2 Rodrigues HG, Diniz YS, Faine LA, Fernandes AAH, Novelli ELB. Suplementação nutricional com antioxidantes naturais: efeito da rutina na concentração de HDL-colesterol. Rev Nutr. 2003; 16 (3): 315-320.

3 Chan K. Some aspects of toxic contaminants in herbal medicines. Chem. 2003; 52 (9): 1316-1371.

4 Tseng TH, Lee MJ, Chou FP, Hsieh MH, Lin MC, Wang CJ. Hibiscus protocatechuic acid or esculetin can inhibit oxidative LDL induced by either copper ion or nitric oxide donor. J Agric Food Chem. 2002; 50 (7): 2130- 2136.

5 Maganha EG. Avaliação da atividade biológica in vitro e in vivo do extrato etanólico das flores de Hibiscus tiliaceus L [Tese]. Universidade Luterana do Brasil Programa de Pós-Graduação Genética e Toxicologia Aplicada; 2009.

6 Kai NS, Nee TA, Ling ELC, Ping TC, Kamariah L, Lin NK. Anti-hypercholesterolemic effect of kenaf (Hibiscus cannabinus L.) seed on high-fat diet Sprague dawley rats. Asian Pacific J. Trop Med. 2015; 8 (1): 6-13.

7 Wang CJ, Wang JM, Lin WL, Chu CY, Chou FP, Tseng TH. Protective effect of Hibiscus anthocyanins against tert-butyl hydroperoxideinduced hepatic toxicity toxicity in rats. Food Chem Toxicol. 2000; 38 (5): 411-416.

8 Moujir L, Seca AM, Lopez MR, Padilla N, Cavaleiro JAS, Neto CP. Cytotoxic activity of lignans from Hibiscus cannabinus. Fitot. 2007; 78 (5): 378-385.

9 Y.G. Lee, S.E. Byeon, J.Y. Kim, J.Y. Lee, M.H. Rhee, S. Hong, J.C. Wu, H.S. Lee, M.J. Kim, D.H. Cho, J.Y. Cho, J. Ethnopharmacol. 2007; 113(1): 62.

10 Kobaisy M; Tellez MR; Webber CL; Dayan FE; Schrader KK; Wedge DE. Phytotoxic and fungitoxic activities of the essential oil of kenaf (Hibiscus cannabinus L.) leaves and its composition. J Agric Food Chem. 2001 Aug; 49(8): 3768-71.

11 Shivali. N., Mahadevan et al., Anti Hypolipidaemic effect of Hydro alcholic extract of Hibiscus cannabinus (L) leaves in the HFD in rats . Ann Biol Research. 2010; 1 (3); 174 - 181.

12 Z.B. Rakhimkhanov, A.S. Sadykov, A.I. Ismailov, A.K. Karimdzhanov, Chem. Nat. Comp.,1970, 6, 124.

13 Reeves PG, Nielsen FH, Fahey GCJR. AIN-93 purifed diets for laboratory rodents: final report of the American Institute of Nutrition
} 
and hoc writing Comitee on the reform olution of the AIN-76 A rodent diet. J Nutr.1993; 123 (11): 1939-1951.

14 Damy SB, Camargo RS, Chammas R, Figueiredo LFP. Aspectos fundamentais da experimentação animal - aplicações em cirurgia experimental. Rev Assoc Med Bras. 2010; 6 (1): 103-111.

15 Panizza S. Plantas que curam - cheiro de mato. 18. ed. São Paulo: Ibrasa; 1997.

16 Goñi I, Calixto SF. Definition of the Mediterranean Diet Based on Bioactive Compounds. Crit Rev Food Sci Nutr. 2009; 49 (2): 145-152.

17 Borba AJ. Efeito da dieta hiperlipídico-protéica no metabolismo de ratos wistar adultos [Dissertação]. Universidade Federal Do Triângulo Mineiro; 2008.

18 Alarcon AFJ, Zamilpa A, Perez GMD, Almanza PJC, Romero NE, Campos SEA, et al. Effect of Hibiscus sabdariffa on obesity in MSG mice. J Ethonopharmacol. 2007; 114 (1): 66-71.

19 Goñi Cl, Mataix VJ. Fibra dietética. 2. ed. Madrid: Ergon; 2009.

20 Ferreira RM, Barreto SLT, Umigi RT, Moraes GHK, Muller ES, Barbosa AA. Perfil da aspartato aminotransferase e alanina aminotransferase e biometria do fígado de codornas japonesas. Rev Bras Zootec. 2010; 39 (2): 308-312.

21 Muriel P. High fat diet and liver damage induced by biliary obstruction in the rat. J Appl Toxicol. 1995; 15 (2): 125-128.

22 Brooks SPJ, Lampi BL. The effect of changing dietary fat and carbohydrate on the enzymes of amino acid metabolism. J Nutr Bioch. 1995; 6 (8): 414-421.

23 Verfaille CJ, Vanhoutte FP, Blanchet BC, Van SMA, Steijlen PM. Oral liarozole vs. acitretin in the treatment of ichthyosis:a phase II/ III multicentre, double-blind, randomized,active-controlled study. Br J Dermatol. 2007; 156 (5): 956-973.

24 TEY HL, THENG TS. Acitretin induced bipedal edema. J Dermatol. 2006; 33 (5): 372-374.

25 Ozaki M, Fuchinue S, Teraoda S, Ota K. The in vivo cytoprotection of ascorbic acid against ischemia/reoxygenation injury of rat liver. Arch Biochem Biophys. 1995; 318 (2): 439-345.

26 Kanhal MA, Ahmad F, Othman AA, Arif Z, Orf S, Murshed KS. Effect of pure and oxidized cholesterol-rich diet on some biochemical parameters in rats. J Food Sci Nutr. 2002; 53 (5): 381-388.

27 Motta VT. Bioquímica Clínica para o Laboratório: princípios e interpretações. 4 ed. São Paulo: Robe; 2003.

28 Anderson JW. Dietary fiber, lipidis and atherosclerosis. Am J Cardiol. 1987; 60 (12): 17-22.

29 Mandal AK, Kalligonis AN, Cohen C, Montgomery RA, Kavousi LR, Ratner LE. Should the right kidney be used in laparoscopic live donor nephrectomy Transplantation. Int Braz J urol. 2005; 69 (5): 116-403.

Recebido em 23 de fevereiro de 2015. Aprovado em 10 de março de 2016. 